\title{
Supplementary Therapeutic Possibilities to Alleviate Myocardial Damage Due to Microvascular Dysfunction in Coronavirus Disease 2019 (COVID-19)
}

\author{
Mihály Medvegy · Gábor Simonyi
}

Received: February 17, 2021 / Published online: April 2, 2021

(C) The Author(s) 2021

\begin{abstract}
Myocardial damage with a consequent rise in cardio-specific troponin level is a frequent phenomenon in severe cases of coronavirus disease 2019 (COVID-19). Its causes are capillary endothelial cell dysfunction, associated carditis, low oxygenization, and increased sympathetic tone, which all worsen myocardial stiffness and microvascular dysfunction (MD). They lead to severe myocardial dysfunction, arrhythmia, acute congestive heart failure, and a significant rise in death cases. During COVID-19, no specific cardiological treatment is started. As adjuvant therapy, anxiolytics in COVID-19 are widely used, but not in all anxious patients who had been infected with coronavirus. Anxiolytics can be useful to moderate MD and immunosuppressive effect of anxiety. The favorable effects of trimetazidine (TMZ) and Coenzyme $\mathrm{Q}_{10}\left(\mathrm{CoQ}_{10}\right)$ in the treatment of myocardial ischemia and heart failure had previously been proven, and also their anti-inflammatory effects had been suspected; however, they have not yet been used in COVID-19 cases. TMZ promotes
\end{abstract}

M. Medvegy $(\bowtie)$

Cardiology Department, Flor Ferenc Hospital,

Kistarcsa, Hungary

e-mail: drmedvegy@hotmail.com

G. Simonyi

Cardiology Department, St Imre Hospital, Budapest, Hungary glucose-mediated ATP production, which requires less oxygen, which explains its advantageous cardiac effects. Since it lowers serum and myocardial tissue proinflammatory cytokine levels and inhibits myocardial macrophage infiltration, it was suspected that TMZ might represent a novel therapeutic agent to prevent and treat sepsis-induced myocardial dysfunction. $\mathrm{CoQ}_{10}$ plays an important role in cellular ATP production; however, its concentration is decreased in cardiovascular diseases and in influenza patients. Due to its anti-inflammatory effect, $\mathrm{CoQ}_{10}$ has been suspected to have a key therapeutic target in influenza infection. We suggest considering these medicines to alleviate myocardial damage and inflammation in COVID-19.

Keywords: COVID-19;

Microvascular dysfunction; Anxiolytics; Trimetazidine; Coenzym-Q $\mathrm{Q}_{10}$ 


\section{Key Summary Points}

Severe cases of coronavirus disease (COVID-19) have microvascular dysfunction, myocardial ischemia, acute congestive heart failure, and a significant rise in death cases.

Trimetazidine and Coenzyme Q10 are important cardiac drugs, though they have not yet been used in the treatment of COVID-19.

Published data were searched to explain the favorable effects of trimetazidine, Coenzyme Q10, and anxiolytics in COVID-19.

We suggest considering these medicines to alleviate myocardial damage and inflammation in COVID-19.

\section{DIGITAL FEATURES}

This article is published with digital features, including a summary slide, to facilitate understanding of the article. To view digital features for this article go to https://doi.org/10.6084/ m9.figshare.14182664.

\section{INTRODUCTION}

Coronavirus infection (COVID-19) first appeared in Wuhan, China, and soon grew into a pandemic. Vaccination, fortunately widely available today, is suspected to be the only possible way to stop the pandemic [1]. At the beginning of March 2020, more than 117 million patients had been diagnosed with COVID19. At the same time, the number of death cases exceeded 2.6 million. Most patients were aged with multiple comorbidities, with cardiovascular diseases at the forefront. COVID-19 infection is usually treated supportively, and therapeutic guidance has been continuously updated [2].
Severe cases require hospital admission, with aggressive respiratory supportive therapy with consideration of antiviral medications [3, 4], corticosteroids, and maybe immunomodulatory drugs and heparin. In addition to those widespread treatment approaches, we would like to discuss the possibility of two more additional supportive, adjuvant therapeutic approaches: trimetazidine (TMZ) and Coenzyme $\mathrm{Q}_{10}$ $\left(\mathrm{CoQ}_{10}\right)$.

This article is based on previously conducted studies and does not contain any new studies with human participants or animals performed by any of the authors.

\section{CARDIAC IMPACT OF COVID-19: MICROVASCULAR DYSFUNCTION (MD) AND TROPONIN RISE}

In COVID-19, the angiotensin-converting enzyme 2 (ACE2) has been identified as the key host cellular receptor of the novel coronavirus SARS-CoV-2. In the heart, the pericytes with high expression of ACE2 might act as the target cardiac cell of SARS-CoV-2. Their injury due to virus infection may result in capillary endothelial cell dysfunction and consecutive MD [5].

The carditis and low oxygenization caused by the respiratory failure can also cause MD and myocardial ischemia, resulting in myocardial damage and acute cardiorespiratory failure [6-8].

The anxiety that often develops in COVID19 can aggravate myocardial damage, which is due to the increase of sympathetic tone, tachycardia, hypertension, and unfavorable metabolic changes, all of which worsen myocardial stiffness and MD. Deterioration of MD alone can cause myocardial ischemia, which could be extended to the entire myocardium (although critical ischemia usually develops earlier in co-existing coronary stenosis). The relationship between anxiety and myocardial ischemia has been verified after earthquakes [9], strokes [10], and in Takotsubo syndrome $[11,12]$. The intense anxiety plays a major role in the unfavorable short- and longterm outcome of ACS [13]. Anxiety experienced 
over a longer period due to cancer [14] or widespread chronic pain [15] causes higher cardiovascular morbidity and mortality.

Anxiety has another harmful effect in COVID-19: it can also exacerbate viral infection [16] due to its immunosuppressive effect: it increases expression of IL-10 and its homolog IL-19 via $\beta$-adrenoceptor activation [17] and suppresses innate IFN- $\gamma$ production via glucocorticoid receptor activation [18].

The MD, myocardial ischemia, arrhythmias, acute heart failure lead to troponin rise. Troponin rise is the most reliable indicator of myocardial damage [19]. Chinese authors documented troponin rise in $20-44 \%$ of all hospitalized COVID-19 patients in various studies; however, troponin rise was higher in cases with cardiovascular comorbidities (ischemic heart disease, hypertension, arrhythmias, heart failure, and diabetes) than in cases without cardiovascular comorbidities (55 vs. 13\%, respectively). The number of deaths was lower in patients without troponin rise (4.5-26\%), and respectively higher with troponin rise $(51-61 \%)[8,20,21]$.

\section{THERAPEUTIC RECOMMENDATIONS}

\section{Anxiolytics}

Clinical evidence has proven the relationship between sympathetic tone and severity of ischemic heart disease. Therefore, anxiolytic drugs are suspected to have a more important role in the prevention and management of ischemic heart disease. In order to support this statement, a multicenter trial (UNWIND) was planned in 2016 [22].

As adjuvant therapy, anxiolytics (mainly benzodiazepines) in COVID-19 are widely used [23], although not in all anxious patients who had been infected with coronavirus. In our opinion, the administration of benzodiazepines should be considered in patients with anxiety and proven COVID-19 when there are no contraindications such as respiratory insufficiency, serious hepatopathy, sleep apnea, myasthenia gravis, or intolerance. In the case of respiratory failure due to COVID-19 pneumonia or other causes, the antidepressants that also have an anxiolytic effect could be considered, such as selective serotonin reuptake inhibitors (escitalopram, venlafaxine, sertraline), with careful dosing in co-existing cardiovascular disease. In severe respiratory insufficiency, other anxiolytic agents can also be considered, such as diphenylmethane derivatives (e.g., hydroxyzine) and azaspirodecanedione derivatives (e.g., buspirone).

\section{Cardiac Agents}

In the case of COVID-19, therapeutic treatment guides have recommended the continuation of previously commenced treatment for ischemic heart disease or other cardiovascular illnesses. However, without previously started treatment, the guides do not recommend starting preventive treatment, such as RAS treatment (ACEI or ARB) [2]. Nevertheless, according to our opinion, based on medical literature, two more pharmacological agents, TMZ and $\mathrm{CoQ}_{10}$, could alleviate the serious cardiac complications in COVID-19.

\section{TMZ}

TMZ was first used as an antianginal, anti-ischemic agent [24-26]. Later, its benefit was also proven in heart failure [27] and TMZ was included into ESC heart failure recommendation [28].

It may affect myocardial substrate use by inhibiting oxidative phosphorylation and shifting energy production from free fatty acids to glucose oxidation. Therefore, this mechanism produces $15 \%$ extra energy, and so reduces oxygen consumption. TMZ prolonged total exercise time and time of appearing symptoms during exercise in microvascular angina [24] and reduced the weekly number of angina attacks in stable angina (3057 patients) [25]. Also, a meta-analysis (evaluating 9856 participants) proved a decrease of weekly angina attacks and nitroglycerin consumption in chronic coronary syndrome [26]. TMZ alleviated temporary myocardial ischemia during 
percutaneous coronary artery intervention (PCI) [27, 28]. However, after PCI, when myocardial ischemia was already non-existent, TMZ did not prove cardiac advantage [29].

TMZ has further favorable biochemical properties: it may also contribute to the preservation of intracellular levels of phosphocreatine and ATP, reduce calcium overload and free radical-induced injury, and inhibit cell apoptosis. All these biochemical features have resulted in favorable clinical effects in heart failure (both in ischemic and non-ischemic), which have been proven by a meta-analysis (17 studies, 955 patients): compared to placebo, trimetazidine significantly improved ejection fraction, New York Heart Association (NYHA) functional state, and exercise capacity [30]. Later, TMZ had "IIbA" recommendation for the treatment of stable angina pectoris with symptomatic (NYHA Class II-IV) heart failure and with reduced ejection fraction (2016 ESC Guidelines for the diagnosis and treatment of acute and chronic heart failure) [31].

It was proven in animal experiments that TMZ lowered levels of proinflammatory cytokines in the serum and in the heart tissue, as well as lowered myocardial macrophage infiltration. Therefore, it was presumed that TMZ might represent a novel therapeutic agent to prevent and treat sepsis-induced myocardial dysfunction [32].

\section{$\mathrm{CoQ}_{10}$}

$\mathrm{CoQ}_{10}$ can be found in all breathing eukaryotic cells, primarily in the mitochondria. It is a component of the electron transport chain and participates in aerobic cellular respiration, which generates energy in the form of ATP (P Mitchell, Nobel award 1978 [33]). $\mathrm{CoQ}_{10}$ has membrane-stabilizing and anti-inflammatory effects and improves endothelial function [34-36]. According to one's diet and the presence of co-existing comorbidities, the blood concentration of $\mathrm{CoQ}_{10}$ varies. Its concentration decreases significantly with old age [36], in chronic heart failure [33, 37], in other cardiovascular diseases, such as hypertension, coronary artery disease, or type 2 diabetes, as well as in neurodegenerative diseases and cancer [33]. This enumeration shows similarity with the risks of serious complications in COVID-19 (age of 65 years or older, male gender, and comorbidities in the following order: cardiovascular disease, diabetes, chronic lung disease, hypertension, and cancer [38]).

The results of a trial proved that patients who had been given $150-180 \mathrm{mg}$ of $\mathrm{CoQ}_{10}$ prior to coronary artery bypass surgery had a lower amount of reperfusion arrhythmias when compared to control subjects [39]. The Q-SYMBIO (2014) trial found that $\mathrm{CoQ}_{10}$ administration lowered the morbidity and mortality in chronic heart failure [40]. In 2017, a meta-analysis (14 studies, 2149 patients) proved that the administration of $\mathrm{CoQ}_{10}(30-100 \mathrm{mg} /$ day) reduced the mortality rate by $31 \%$ in heart failure patients, compared to the control group (where patients did not receive $\mathrm{CoQ}_{10}$ ). Furthermore, exercise capacity was increased in the therapeutic group. No significant difference was found in the endpoints of left heart ejection fraction and NYHA classification [41].

Because of its anti-inflammatory effect, $\mathrm{CoQ}_{10}$ was also investigated in influenza. $\mathrm{CoQ}_{10}$ levels in influenza patients were significantly lower than in healthy controls. It had a significant (albeit weak) correlation with several inflammatory biomarkers; however, not with those which have been implicated in influenza pathogenesis (IL-6). Further investigations were suggested to determine whether $\mathrm{CoQ}_{10}$ could represent a key therapeutic target in influenza infection [42].

\section{ATP in Viral Infection}

According to a large amount of evidence, both $\mathrm{TMZ}$ and $\mathrm{CoQ}_{10}$ could be assumed to be beneficial in COVID-19, primarily due to reducing cardiac complications. However, it is questionable whether the externally administered ATP (by $\mathrm{TMZ}$ and/or $\mathrm{CoQ}_{10}$ ) will facilitate the viral replication [43]. Zhang et al. have already confirmed this with animal experiments so far, where innate immune responses are associated with extracellular nucleotides, particularly ATP. They had found extensive protection of ATP/ 
P2X7 signaling against viral infection in a host, and demonstrated that extracellular ATP reduces the replication of several viruses [44].

\section{CONCLUSIONS}

While anxiety can cause/worsen MD, anxiolytics could be considered as adjuvant therapy in anxious COVID-19 patients when there are no contraindications.

TMZ and $\mathrm{CoQ}_{10}$ were not used in COVID-19 earlier, therefore their benefit in COVID-19 is based only on a hypothesis. Since it is known that COVID-19 can cause/worsen MD, consecutive myocardial ischemia, and heart failure, administering these drugs as adjuvant therapy seems to be well founded, as several studies proved the favorable effects of these drugs in the treatment of myocardial ischemia and heart failure.

In conclusion, we suggest considering TMZ and $\mathrm{CoQ}_{10}$ as adjuvant therapy to alleviate myocardial damage in COVID-19.

\section{ACKNOWLEDGEMENTS}

We would like to thank Dr. Zs K. Horváth, MD, for her advice.

Authorship. All named authors meet the International Committee of Medical Journal Editors (ICMJE) criteria for authorship for this article, take responsibility for the integrity of the work as a whole, and have given their approval for this version to be published.

Compliance with Ethic Guidelines. This article is based on previously conducted studies and does not contain any new studies with human participants or animals performed by any of the authors.

Disclosures. Mihály Medvegy and Gábor Simonyi have nothing to disclose.

Data Availability. Data sharing is not applicable to this article, as no datasets were generated or analyzed during the current study.
Funding. The journal's Rapid Service Fee was sponsored by Servier.

Open Access. This article is licensed under a Creative Commons Attribution-NonCommercial 4.0 International License, which permits any non-commercial use, sharing, adaptation, distribution and reproduction in any medium or format, as long as you give appropriate credit to the original author(s) and the source, provide a link to the Creative Commons licence, and indicate if changes were made. The images or other third party material in this article are included in the article's Creative Commons licence, unless indicated otherwise in a credit line to the material. If material is not included in the article's Creative Commons licence and your intended use is not permitted by statutory regulation or exceeds the permitted use, you will need to obtain permission directly from the copyright holder. To view a copy of this licence, visit http://creativecommons.org/licenses/by$\mathrm{nc} / 4.0 /$.

\section{REFERENCES}

1. Pllard AJ, Bijker EM. A guide to vaccinology: from basic principles to new developments. Nat Rev Immunol. 2021;21:83-100.

2. COVID-19 treatment Guidelines. An official website of the National Institutes of Health. http://www. covid19treatmentguidelinesnih.gov. Accessed 5 Mar 2021.

3. Klopfenstein T, Zayet S, Lohse A, Balblanc JC, Bodie $\mathrm{J}$, Royer PY, et al. Tocilizumab therapy reduced intensive care unit admissions and/or mortality in COVID-19 patients. Med Mal Infect. 2020;50: 397-400.

4. Beigel JH, Tomashek KM, Dodd LE, Mehta AK, Zingman BS, Kalil AC, Hohmann E, Chu HY, Luetkemeyer A, Kline S, de Castilla DL, Finberg RW, et al. Remdesivir for the treatment of Covid-19 final report. N Engl J Med. 2020;2020(383): 1813-26. https://doi.org/10.1056/NEJMoa2007764.

5. Chen L, Li X, Chen M, Feng Y, Xiong C. The ACE2 expression in human heart indicates new potential mechanism of heart injury among patients infected with SARS-CoV-2. Cardiovasc Res. 2020;116(6): 
1097-100. https://doi.org/10.1093/cvr/cvaa078 (Published 30 Mar 2020).

6. Madjid M, Safavi-Naeini P, Solomon SD, et al. Potential effects of coronaviruses on the cardiovascular system. A review. JAMA Cardiol. 2020. https:// doi.org/10.1001/jamacardio.2020.1286 (Published online 27 Mar 2020).

7. Kim I, Kim JY, Kim HA, Han S. COVID-19-related myocarditis in a 21-year-old female patient. Eur Heart J. 2020. https://doi.org/10.1093/eurheartj/ ehaa288 (Published 13 Apr 2020).

8. Guo T, Fan Y, Chen M, Wu X, Zhang L, He T, et al. Cardiovascular implications of fatal outcomes of patients with coronavirus disease 2019 (COVID-19). JAMA Cardiol. 2020. https://doi.org/10.1001/ jamacardio.2020.1017 (Preliminary electric publication: 2020.03.27).

9. Kario K, McEven SB, Pickering T. Disasters and the heart: a review of the effects of earthquake-induced stress on cardiovascular disease. Hypertens Res. 2003;26:355-67.

10. Kerr G, Ray G, Wu O, Stott DJ, Langhorne P. Elevated troponin after stroke: a systematic review. Cerebrovasc Dis. 2009;28:220-6.

11. Vitale C, Rosano G, Kaski JC. Role of coronary microvascular dysfunction in Takotsubo cardiomyopathy. Circ J. 2016;80:299-305.

12. Meye P, Degrauwe S, Van Delden C, Ghadri JR, Templin C. Typical takotsubo syndrome triggered by SARS-CoV-2 infection. Eur Heart J. 2020. https:// doi.org/10.1093/eurheartj/ehaa306 (Published 14 Apr 2020).

13. Polikandriotti M, Olympios C. Anxiety and coronary artery disease. Arch Hell Med. 2014;31(4): 403-11.

14. Guha A, Dey AK, Jneid H, Addison D. Acute coronary syndromes in cancer patients: the differences of ACS in cancer patients and the general population are discussed. Eur Heart J. 2019;40:1487-90.

15. Tesarz J, Eich W, Baumeister D, Kohlmann T, D'Agostino R, Schuster AK. Widespread pain is a risk factor for cardiovascular mortality: results from the Framingham Heart Study. Eur Heart J. 2019;40: 1609-17.

16. Coughlin SS. Anxiety and depression: linkages with viral diseases. Public Health Rev. 2012;34:7. https:// doi.org/10.1007/BF03391675 (Published online 9 Dec 2012).

17. Curtin NM, Mills KHG, Connor TJ. Psychological stress increases expression of IL-10 and its homolog
IL-19 via $\beta$-adrenoceptor activation: reversal by the anxiolytic chlordiazepoxide. Brain Behav Immun. 2009;23:371-9.

18. Curtin NM, Boyle NT, Mills KHG, Connor TJ. Psychological stress suppresses innate IFN- $\gamma$ production via glucocorticoid receptor activation: Reversal by the anxiolytic chlordiazepoxide. Brain Behav Immun. 2009;23:535-47.

19. Lippi G, Lavie CJ, Sanchis-Gomar F. Meta-analysis on troponin I in patients with coronavirus. Prog Cardiovasc Dis. 2020;63:390-1.

20. Zhou F, Yu T, Du R, et al. Clinical course and risk factors for mortality of adult inpatients with COVID-19 in Wuhan, China: a retrospective cohort study. Lancet. 2020;395:1054-62.

21. Shi S, Qin M, Shen B, Cai Y, Liu T, Yang F, et al. Association of cardiac injury with mortality in hospitalized patients with COVID-19 in Wuhan, China. JAMA Cardiol. 2020;5:802-10.

22. Blumenthal JA, Feger BJ, Smith PJ, Watkins LL, Jiang W, Davidson J, Hoffman BM, Ashworth M, Mabe SK, Babyak MA, Kraus WE, Hinderliter A, Sherwood A. Treatment of anxiety in patients with coronary heart disease: rationale and design of the UNWIND randomized clinical trial. Am Heart J. 2016;176:53-62.

23. Pesce NL. Anti-anxiety medication prescriptions have spiked $34 \%$ during the coronavirus pandemic. MarketWatch The Margin. https://www. marketwatch.com/story/anti-anxiety-medicationprescriptions-have-spiked-34-during-thecoronavirus-pandemic-2020-04-16. Accessed 16 Apr 2020 .

24. Nalbantgil S, Altintig A, Yilmaz H, Nalbantgil T, Önder R. The effect of trimetazidine in the treatment of microvascular angina. Int J Angiol. 1999;8: $40-3$.

25. Glezer MG, Vygodin VA, on behalf of ODA investigators. Effectiveness of long-acting trimetazidine in different clinical situations in patients with stable angina pectoris: findings from ODA trial. Cardiol Ther. 2019;8:69-78.

26. Nagy VL, Herold Z. Clinical effect of various trimetazidine formulations in chronic coronary syndrome. Orvosi Hetil. 2020;161(16):611-22.

27. Labrou A, Giannoglou G, Zioutas D, Fragakis N, Katsaris G, Louridas G. Trimetazidine administration minimizes myocardial damage and improves left ventricular function after percutaneous coronary intervention. Am J Cardiovasc Drugs. 2007;7(2):143-50. 
28. Zhang Y, Ma XJ, Shi DZ. Effect of Trimetazidine in patients undergoing percutaneous coronary intervention: a meta-analysis. PLoS ONE. 2015;10(9): e0137775. https://doi.org/10.1371/journal.pone. 0137775 (Published online 14 Sep 2015).

29. Ferrari R, Ford I, Fox K, Challeton JP, Correges A, Tendera $\mathrm{M}$, et al. Efficacy and safety of trimetazidine after percutaneous coronary intervention (ATPCI): a randomized, double-blind, placebo-controlled trial. Lancet. 2020;396:830-8.

30. Gao D, Ning N, Niu X, et al. Trimetazidine: a metaanalysis of randomised controlled trials in heart failure. Heart. 2011;97:278-86.

31. Ponikowski P, Voors AA, Anker SD, et al. 2016 ESC Guidelines for the diagnosis and treatment of acute and chronic heart failure: the task force for the diagnosis and treatment of acute and chronic heart failure of the European Society of Cardiology (ESC). Developed with the special contribution of the Heart Failure Association (HFA) of the ESC. Eur Heart J. 2016;37(27):2129-200. https://doi.org/10. 1093/eurheartj/ehw128 (Epub 20 May 2016).

32. Chen J, Lai J, Yang L, Ruan G. Trimetazidine prevents macrophage mediated septic myocardial dysfunction via Sirt 1. Br J Pharmacol. 2015. https:// doi.org/10.1111/bph.13386.

33. Rodick TC, Seibels DR, Babu JR, Huggins KW, Ren G, Mathews ST. Potential role of coenzyme Q10 in health and disease conditions. Nutr Diet Suppl. 2018;10:1-11.

34. Turunen M, Olsson J, Dallner G. Metabolism and function of coenzyme Q. Biochim Biophys Acta. 2004;1660:171-99.

35. Zhai J, Bo Y, Lu Y, Liu C, Zhang L. Effects of coenzyme Q10 on markers of inflammation: a systematic review and meta-analysis. PLoS ONE. 2017. https://doi.org/10.1371/journal.pone.0170172 (Published 26 Jan 2017).

36. Judy WV. The substance that powers lives. Coenzyme $\mathrm{Q}_{10}$. An insider's Guide. Forlaget Ny Videnskab. 2018;5-163. ISBN 978-87-7776-1086-7.
37. Molyneux SL, Florkowski CM, George PM, Pilbrow AP, Frampton CM, Lever M, Richards AM. Coenzyme Q10 an independent predictor of mortality in chronic heart failure. J Am Coll Cardiol. 2008;52(18):1435-41. https://doi.org/10.1016/j. jacc.2008.07.044.

38. Age, sex, existing conditions of COVID-19 cases. Worldometer. https://www.worldometers.info/ coronavirus/coronavirus-age-sex-demographics/. Accessed 13 May 2020.

39. Makhija N, Sendasgupta C, Kiran U, et al. The role of oral coenzyme Q10 in patients undergoing coronary artery bypass graft surgery. J Cardiothorac Vasc Anesth. 2008;22:832-9.

40. Mortensen SA, Rosenfeldt F, Kumar A, et al. The effect of Coenzyme Q10 on morbidity and mortality in chronic heart failure. Results from Q-SYMBYO: a randomized double-blind trial. J Am Coll Card Heart Fail. 2014;2:641-9.

41. Lei L, Liu Y. Efficacy of coenzyme Q10 in patients with cardiac failure: a meta-analysis of clinical trials. BMC Cardiovasc Disord. 2017;17:196. https:// doi.org/10.1186/s12872-017-0628-9 (Published online 24 Jul 2017).

42. Chase M, Cocchi MN, Liu X, Andersen LW, Holmberg MJ, Donnino MW. Coenzyme Q10 in acute influenza. Influenza Other Respir Viruses. 2019;13(1):64-70. https://doi.org/10.1111/irv. 12608 (Published online 30 Sep 2018).

43. Nagy PD, Lin W. Taking over cellular energymetabolism for TBSV replication: the high ATP requirement of an RNA virus within the viral replication organelle. Viruses. 2020;12(1):56. https://doi.org/10.3390/v1201005.

44. Zhang C, He H, Wang L, Zhang N, Huang H, Xiong Q, Yan Y, Wu N, Ren H, Han H, Liu M, Qian M, Du B. Virus-triggered ATP release limits viral replication through facilitating IFN- $\beta$ production in a P2X7-dependent manner. J Immunol. 2017;199(4): 1372-81. https://doi.org/10.4049/jimmunol. 1700187 (Epub 7 Jul 2017). 